\title{
THE ROLE OF HEALTH INSURANCE AND MANAGED CARE IN INDIA
}

\author{
Sham Ranjan Shetty * \\ T A Pai Management Institute, Manipal, Karnataka, India \\ Manipal Academy of Higher Education, Manipal, Karnataka, India \\ Debmallya Chatterjee \\ S P Jain Institute of Management and Research, Mumbai, India
}

\section{Yogesh P Pai}

Manipal Institute of Management, Manipal Academy of Higher Education,

MIT Campus, Manipal, Karnataka, India

*Corresponding Author

\begin{abstract}
By 2022, the Indian healthcare industry is projected to rise to US\$ 372 billion, powered by increased revenue, enhanced health literacy, lifestyle diseases and increased access to insurance. The healthcare industry is a significant and developing research context that can be defined by a strong emphasis on individualized products and a distinguished need for a variety of dispersed supply chain players to collaborate. The ever-rising cost of health care, combined with the need for health care services, the lack of convenient access to affordable health care for people from low-income groups have contributed to the rise of health insurance as an alternate method for funding health care. This article attempts a scoping review of literature on Indian health insurance and the major topics discussed in those articles. Review of the developments and the issues in the Indian insurance industry would enable a clearer understanding of the current level of research and the future directions which is the motivation for the study.
\end{abstract}

Key words: Indian health insurance, Managed Care, Third Party Administrator (TPA), Health insurance cost and claims management.

Cite this Article: Sham Ranjan Shetty, Debmallya Chatterjee and Yogesh P Pai, The Role of Health Insurance and Managed Care in India, International Journal of Management, 11(12), 2020, pp 679-692.

http://iaeme.com/Home/issue/IJM?Volume=11\&Issue=12 


\section{INTRODUCTION}

By 2022, the Indian healthcare industry is projected to rise to US\$ 372 billion, powered by increased revenue, enhanced health literacy, lifestyle diseases and increased access to insurance (IBEF, 2020). Access to high quality health care is seen as a vital basis for eliminating socio-economic and ethnic inequalities and enhancing the quality of life for all people. Given both the importance of quality and safety in providing patient care, healthcare is an especially important service sector (McFadden, Stock, Gowen III, \& Cook, 2006), and the associated cost (Dobrzykowski, Saboori Deilami, Hong, \& Kim, 2014). The healthcare industry is a significant and developing research context that can be defined by a strong emphasis on individualized products and a distinguished need for a variety of dispersed supply chain players to collaborate (Boyer \& Pronovost, 2010; De Blok, Meijboom, Luijkx, \& Schols, 2013).

The ever-rising cost of health care, combined with the need for health care services, the lack of convenient access to affordable health care for people from low-income groups has contributed to the rise of health insurance as an alternate method for funding health care. Historically, health insurance has contributed by playing a central role in improving health care gain access around the world. In most Asian countries, out-ofpocket (OOP) costs are the key source of healthcare funding, and India is no exception. Health sector improvements in India have been fragmentary and gradual, but have led to major improvements in the formation, structure and delivery of healthcare services and funding (Sen, Iyer, \& George, 2002). In the 1990s, public investment in the health sector was further squeezed at the state level (Dev \& Mooij, 2002), resulting in a failure by the government to even meet the health needs of the public. When investment in public health declined and public sector user fees rose, the private sector came in to utilise the business opportunity (Peters, 2002). These health sector changes are expected to drive OOP health payments upwards in public as well as private hospitals, and these rises are likely to impact the usage of health services and overall health care in turn (Ghosh, 2010). Private spending pays for over $80 \%$ of health funding, all being out of pocket contributions and not by any pre-payment systems. Considering the healthcare financing and demand situation, in India's current situation, health insurance has a broader reach. However, deliberate and substantial efforts are required to tap into the Indian health insurance market with proper understanding and preparation (Anita, 2010). New legislation may also be required to strengthen requirements for the delivery of health care. In this scenario, the creation of health insurance was one of the ways in which the government minimized under-funding and increased resources in the health sector. The rising cost of health care, combined with the need for health care services, the lack of accessible quality health care for people from the low income community have resulted in health insurance emerging as an alternative method for health care financing.

India's health care is seriously underfunded and both the government and the public do not have the financial resources to pay for medical care of acceptable quality. Therefore, India is faced with the daunting challenge of meeting its population's healthcare demands and ensuring accessibility, productivity, equality, and healthcare quality. Given this scenario, private health insurance must be generally accepted in the sector and play an important role in solving the gap in health care financing. But in fact, in an unsustainable way, the industry has been stalled by restrictive regulations and obsolete business models and persists to operate under losses. K. Thomas and Vel (2011) note that there are many challenges facing health insurers in India at present, including weak knowledge, low product recognition, and vague business profitability. Insurers 
must innovate their product offerings and strengthen their existing procedures and cost structures within their current system.

\section{LITERATURE REVIEW}

In many countries, health insurance is very well known, but it still remains an untapped market in India. Of India's 1.1 billion population, fewer than 15 percent are covered by health insurance. In FY20, total direct premium underwritten by health insurance increased $17.16 \%$ y-o-y to Rs $51,637.84$ crore (US\$ 7.39 billion). (IBEF, 2020). Health insurance is emerging rapidly as a significant tool for funding people's healthcare needs (Anchan, Jathanna, \& Marla, 2011; Bhat \& Reuben, 2002). Historically, health insurance has played a central role in enhancing health care access over the world. In India, the growing level of middle-class income has led to the rise of lifestyle-related illnesses. This has elicited the need for health insurance, amid inflationary health care prices. Given the diversity of the population of India and its limited buying power, to penetrate this huge market, innovative insurance products are needed at several price points. Both existing companies and new entrants agree that the Indian health insurance market has emerged as a new and lucrative developing avenue. Governments have found that providing health care premiums instead of healthcare services by hospitals is much safer for them. In order to obtain the same corporate treatment for illnesses, governments have launched many health care programs for disadvantaged people.. The Insurance Regulatory and Development Authority (IRDA) was established by the central government as a regulatory body for the entire industry (Mavalankar \& Bhat, 2000). In healthcare, the current emphasis is on universal health coverage, along with the reduction in total health expenditures. Exploring performance assessment and benchmarking finds a prominent position in healthcare research with the rapid speed of growth and spending on healthcare. The increasing cost of delivering healthcare services has generated pressure to recognize the root cause of these growing costs and find ways to rationalize the cost of healthcare in the country (Smith, Nachtmann, \& Pohl, 2011). Instead of offering a solution to these problems, India's health financing structure is a source and an aggravating element in the challenges of health disparities, insufficient availability and scope, unequal access, and poor-quality and expensive health care services (Khan \& Banerji, 2014).

Companies need to assess the emerging business models of managed care, centralized delivery and responsible care at a more strategic level, which will force wholesale improvements in the healthcare sector and help create a viable and sustainable model of insurance. The evidence on the effect of health insurance in low and middle income countries was analysed and it was found that health insurance increased coverage and usage but had no definitive impact on health status. Spaan et al. (2012) examined the effects of health insurance in African and Asian low- and lower-middleincome countries and discovered a "incomplete,.. patchy and variable quality" evidence base. Additional studies on the impact of health insurance gives conflicting evidence of the impact of health insurance on health outcomes for high-income populations and insufficient data for low- and middle-income populations. Government and private companies will need to concentrate on aspects of benefit design, pricing and knowledge transparency in order to expand the reach and viability of private health insurance policies, and explain requirements on coverage standards and provider quality standards (Bhattacharjya \& Sapra, 2008). The pooling of capital to cover risks is assured by an effective framework. In India, health insurance is at a emerging stage and contributes to a limited percentage of health spending. The government has played an important role through its state-run programmes, such as the the Central Government Health Scheme 
(CGHS), Employee State Insurance Scheme (ESIS) and the Mediclaim scheme provided by government-run insurance firms. Insurance firms have to compete with unregulated health care providers working in an setting where there are no guidelines, treatment protocols and quality standards, and where there are extremely inconsistent billing schemes and large price differences among providers (echoed by the adverse claim ratios). It has also been noted that hospitals charge too much from the patients covered by insurance, but it is difficult to deal with false claims in the dearth of monitoring and control mechanisms. Intermediaries like third party administrators (TPAs) are critical and are required to play a key role in the creation and growth of a managed health care system in order to solve these problems (Bhat \& Babu, 2004).

Insurers can also make certain that the customer has a financial motivation to monitor costs and optimize their savings by selling products by which the consumer can manage their health care funds. Consumers thus are likely to be self-managed and become more prudent with the use of healthcare facilities (Dixon, Greene, \& Hibbard, 2008). As far as risk modelling is concerned, Indian health insurers are hampered by the absence of a government order to retain health insurance for people. The definition of health insurance has yet to be fully understood and appreciated by the government and consumers in India (Berman, 1998). Primary care dependent on insurance has become increasingly complicated, inefficient, and restrictive, motivating dissatisfied doctors and patients to search for alternatives. Direct primary care is an increasingly adopted form of health care that not only eases such frustrations, but even goes beyond providing expanded access and enhanced care at an affordable price. In addition, while insurers and lawmakers also support changes that make up for quality instead of quantity, such as value-based hospital purchases and efficiency payments for doctors, it remains to be seen if these moderate payment reforms will shift the nature of care (McCorry, 2014).

$\mathrm{K}$. Thomas and Vel (2011) mention that in India, health insurers are presently faced with many challenges, including low acceptance of products, weak awareness and ambiguous market profitability. Insurers need to transform their product offerings and make tighter procedures and cost structures within their current system. Companies need to assess the emerging business models of managed care, centralized delivery and responsible care at a more strategic level, which will force wholesale improvements in the healthcare sector and help create a more viable model of insurance. The health insurance industry requires to reconsider its business models and analyze new health care principles that can help address the discrepancy and help the sector work efficiently. The integrated model, managed care model and accountable care model are some of the frameworks that health insurers need to assess (ACM). These models will assist health insurers tackle the main problems of health care costs, quality control and will help the sector address the challenges of the industry. Though these models have been used in other nations, Indian health insurers must take into account the indigenous context and make certain that models operate efficiently for all stakeholders and address the health care challenges of the country effectively (K. Thomas \& Vel, 2011). Health insurers need to move towards more difficult capitation models of hospital payment for the long term (Sulger, 1996; Trude, Au, \& Christianson, 2006).

Managed care models have been attempted and tested globally and provide numerous levers to monitor and control medical expenses. The favoured model for health insurance is managed care in the United States, which is the world's biggest health sector. Few of the managed care solutions that Indian health insurers will pursue are items with variable benefits and optimal arrangements for providers, including variable rate tiered hospital networks varying on the type of provider. Indian insurers need to 
analyze and implement these levers to enhance their operational metrics to the managed care levers that will be applicable in the Indian context (T. K. Thomas, 2011). Different health care models and performance metrics have emerged as crucial elements for cost control, as pressure from government, insurance providers, societies, and individual patients to minimize costs and improve the quality of health care rises. The burden of health care expenses has been transferred to third parties who in a cost-based system, pay health care providers (L. Li \& Benton, 1996).

The introduction of accountable care organizations (ACOs), a new compensation and delivery model for healthcare intended to optimize care and minimize costs, is proceeding rapidly. In answer to an increasing awareness that fee-for-service payments were significant reasons for the rapidly growing costs and ill organized treatment that depict the US health care system, the ACO definition emerged. Provider associations eager to be responsible for the quality and total costs of treatment for their patients are entitled for a portion of the savings gained by enhancing care under this new payment model. A systematic assessment initiative that lasts for several years would be needed to build a solid evidence base to answer the concerns that payers, policy makers, and providers have about ACOs (Fisher, Shortell, Kreindler, Van Citters, \& Larson, 2012). Accountable care organizations, scheduled under the Affordable Care Act to become part of the Medicare program, have been marketed as a way to enhance the quality of health care, minimize cost growth and increase the satisfaction of patients. The model has a dynamic leadership role that overcomes health care fragmentation and forges payment agreements to compensate providers for meaningful changes in health outcomes. ACOs need to build the skills required to negotiate new forms of payer contracts so that financial gains associated with keeping individuals well and out of the health care system are not only absorbed by employers, but are split with providers instead.. In addition, ACOs must view payers in a somewhat different way, step away from adversarial bargaining on payment rates and instead see them as stakeholders that share risk in enhancing the entire health status of the insured population (DeVore \& Champion, 2011).

The functions of the provider and the insurer are combined by managed care institutions such as HMOs that have arisen in the private sector and can also help to cut costs. There is some evidence that the advent of HMOs has contributed to cost containment in the United States (Mahal, 2002). The Insurance Regulatory and Development Authority, in India, has paved the way for insurance intermediaries such as third-party administrators (TPAs) to play a key role in the establishment of managed health care schemes in order to offer better coverage to policyholders and to moderate some of the negative impact of health insurance. The position of TPAs has been described by IRDA as one of claim and reimbursement management. Their position in managing healthcare expenditures and making sure sufficient quality of care is defined (Bhat \& Babu, 2004). The TPA model did not succeed in lowering the cost of the claim, but helped to provide impartial services, including cashless benefits. Managed care models have been internationally tried and tested and provide many levers to track and manage patient costs. Regulated care in the US, which is the world's largest health market, is the preferred standard for health insurance. Models promoting financial cost sharing between members and hospitals can also be embraced by health insurers. (T. K. Thomas, 2011).

Pay-for-performance ( $p 4 p)$ arises from frustration with systems of payment that compensate the sum rather than the standard of health care services. It arose as part of the backlash against managed care, which seemed to have tamed cost inflation for a few 
years, but raised questions about inadequate access restrictions and increasing evidence across the health system of quality deficiencies (Robinson, Williams, \& Yanagihara, 2009). Managed care focuses on managing patient demand and does not adequately resolve fragmentation, and an integrated approach of centralized funding and distribution is an efficient option for a decentralized health care system. For most insurance providers, health insurance is a non-profitable line of business. This is commonly thought to be because hospitals appear to inflate the bills until they know that the patient's tab will be taken up by an insurance provider. TPAs are intermediaries who on behalf of insurance firms, handle claims. The experience with TPAs, however was not pleasant. Therefore, the notion of a 'captive' TPA has been dealt with by PSU insurers. Around four years ago, the concept of forming a TPA joint venture was first suggested as insurance firms struggled with poor service charges, delays and consumer disputes. One of the latest changes was to bring TPA facilities in-house in order to save TPA fees and improve customer support (Mehta, 2010). Based on the utilization of medicines, diagnostics, outpatient and hospital care, physicians and physicians (service providers) have complete control over the volume of demand for their services. The most predominant mechanism for managing consumer demand and spreading financial responsibility is the managed care model. At the heart of the Accountable Care Model, which is the foundation for hospital compensation relating to quality improvements and cost savings, are advanced quality, cost and performance assessment mechanisms. This will also ensure transparency by specifically specified cost and quality performance indicators and through which reimbursement incentives for defined patient groups will be correlated with increased quality and reduced costs (Mark McClellan, McKethan, Lewis, Roski, \& Fisher, 2010; K. Thomas \& Vel, 2011). Indian insurers need to evaluate and implement these levers to strengthen their operating metrics for certain levers of managed care that would be relevant in the Indian setting. (T. K. Thomas, 2011).

Porter and Teisberg (2006) feel that there is a specific and significant position for health insurers in value-based competition and healthcare innovation. They emphasize that health insurers have to rethink and reorient their whole approach to value-based rivalry. Health insurers must become health associations dedicated to patient and provider data, support and operation, not just administrative, auditing and financial services firms. Therefore, in consumer satisfaction growth, health insurers need to move from becoming opponents to true allies. There is an incentive for insurance firms to create long-term relationships with chosen healthcare services by understanding each other's positions in serving the common customer. The use of technologies would help overcome the current service gap and contribute to increased service quality, better transparency and cost-effectiveness. Insurance companies need to develop plans that take account of the multiple market trends and predict the changes that the sector is bound to see (Reddy et al., 2011). Pay for results, emerging in the US and UK as a creative and effective payment system, should also be considered to increase the standard of treatment in conjunction with other prospective payment methods (Doran et al., 2006; Rosenthal \& Dudley, 2007). Many countries including the United States, have concluded that the use of primary health care providers as guardians for specialized facilities and hospital care in their managed care plans is a valuable cost containment mechanism (Ros, Groenewegen, \& Delnoij, 2000), but it also relies on well-performing primary health systems and efficient regulation of health care facilities (Lawn, Harries, Anglaret, Myer, \& Wood, 2008; C. Li, Yu, Butler, Yiengprugsawan, \& Yu, 2011).

There is a prospect for insurance companies to develop long-term partnerships with the selected providers of healthcare by leveraging technology and recognizing the roles of each other in supporting the common client. One of the main contributors to 
maintaining this rapid development would be the programs provided by insurance providers, calculated mainly by cashless services. A classic dilemma for health officials and researchers is how to build a healthcare system that can track or moderate the exponential growth in healthcare costs without unduly compromising the quality of and access to health services. The findings show that the insurance provider or the TPA would have a relative advantage over its rivals only if by a cooperative arrangement, it is possible to freeze up the fees/packages for a period of around three to five years. Using technology will help bridge the existing service gap and lead to improved efficiency of the service, greater accountability and cost-efficiency. Insurance companies need to develop plans that take account of the multiple market trends and predict the changes that the sector is bound to see (R. Kumar, Rangarajan, \& Ranganathan, 2011). Here by handling claims and extending cashless benefits to their network suppliers, the TPA acts as a 'service bridge' between the insured and the insurer. Such providers (hospitals) are spread across India and are a significant factor in deciding the cost of the claim. The cost of compensation is directly proportional to the insured's premium, i.e. the insurance premium always falls with the cost of claims being raised, and vice versa. We have seen the issue of rising premiums for health insurance plans worldwide. The concept of treatment protocols that define adequate medical care for a array of diseases is a viable first step towards solving this issue. The insurer may give the discretion to the physician that the disease has arisen, while also maintaining some influence over the services rendered Patients receiving care from doctors who appear to surpass the protocol of treatment may be expected to pay extra premiums. A classic dilemma for health officials and researchers is how to build a healthcare system that can track or moderate the exponential growth in healthcare costs without unduly compromising the quality of and access to health services. In the cyclical process of premium premiums and claims expenses, the latter has a strong bearing on the bottom line, and steps to better control the same would be one of the key success factors. Since consumer demand for medical services is regulated by health care companies and the cost of healthcare is paid by premiums (through the health insurance mechanism), there is no effort by providers to minimize the cost or inefficient use of resources, contributing to an increase in health expenditure. A difficult question, then, is how to persuade providers to be cost-effective or how to implement a cost-sharing arrangement on the supply side to make providers bear the economic consequences of their actions in health care growth.

\section{METHODOLOGY}

The article attempts to review literature on Indian health insurance and the major topics covered in those articles. Review of the developments and the issues in the Indian insurance industry would enable a clearer understanding of the current level of research and the future directions which is the motivation for the study. Articles dealing with health insurance in general and India in specific have been included and themes and issues from these articles are discussed in this study.

\section{FINDINGS AND DISCUSSION}

India's health financing system is creating and exacerbating the problems of health disparities, insufficient coverage and availability, differential access, and low quality and expensive health care services. Increased federal funding would be used to introduce affordable medical coverage, helping to significantly lower the burden of out-of-pocket private spending on medicine. However the Government of India will need to introduce specific cost-capture measures, boost budget efficiency, enhance transparency and control the effects of health spending in addition to rising public expenditure on health 
(A. S. Kumar et al., 2011). The government has recognized that offering health insurance rather than health care services by hospitals is much safer for them. In order to obtain the same corporate treatment for illnesses, governments have launched many health care programs for disadvantaged people (Mavalankar \& Bhat, 2000). In all stages, decisionmakers need to measure the uncertainty in the success of the health system, recognize variables that impact it and articulate strategies that can produce improved outcomes in a range of environments. We agree that the role of governments, development agencies and multilateral organizations needs a compelling and operational mechanism for evaluating the performance of the health system (Murray \& Frenk, 2000). Developing nations that have turned universal health services into insurance-based health programs under structural reform strategies have struggled to supply the vulnerable with healthcare (Duggal, 2012). In order to broaden the scope and feasibility of private health insurance policies, the government and private sectors will need to work on issues of pricing, benefit design and availability of information and clarify expectations on policy specifications and quality standards for providers (Bhattacharjya \& Sapra, 2008).

Researchers are gradually accepting that it is much more important to create rewards for provider actions to accomplish cost control than to create market incentives focused on cost-sharing (Liu, Hsiao, Li, Liu, \& Ren, 1995). Pay for results, evolving in the US and UK as a creative and effective payment system, can also be considered to increase the standard of treatment in tandem with other prospective payment systems (Doran et al., 2006; Rosenthal \& Dudley, 2007). Many countries including the United States, have found that through their controlled care plans, the use of primary health care services as gatekeepers for specialist facilities and hospital treatment is a valuable cost containment mechanism (Ros et al., 2000), but it also focuses on well-functioning primary health care services and efficient management of health care (Lawn et al., 2008). Controlling the market for health insurance is another major issue in India due to the shortage of financial health coverage offered to most Indians. The health insurance market is made up of a variety of providers providing compulsory social health insurance, charitable private health insurance, and community-based health insurance policies. The direct effect on the standard of care of the attempt to set up TPAs, however will remain negligible unless it is combined with a concurrent move to create a reliable mechanism of overseeing providers, such as through uniform licensing and accreditation systems. Without these organizations, any insurer should be obliged to establish its own accreditation scheme and reimbursement procedures through the usual process of rivalry. Showing a more serious approach to health coverage would also offer effective means of matching the government's health care spending with its defined equity and poverty reduction goals, as well as having a better influence on the activities of providers (Bloom, Kanjilal, \& Peters, 2008).

The government seems to have been lethargic in forecasting changes, at least as far as health insurance is concerned, in comparison to the hectic operation in the private sector. The policy climate in India, where health care tends to be ignored, is broadly representative of this. There is an prospect for insurance firms to develop long-term partnerships with the chosen providers of health care by leveraging technologies and recognizing the roles of each other in supporting the common customer. Substantial research has been undertaken in developing countries aimed at clarifying the actions of caregivers and reduction the cost of healthcare. Porter and Teisberg (2006) mention that the relationship between health insurers and healthcare service providers has to be restructured in such a manner that an adversarial strategy between health insurers and healthcare service providers promotes a spirit of collaboration in terms of patient value development. When private insurers and healthcare service providers combine together 
around value and patient benefits, productivity grows exponentially, and administrative costs drop. Developing nations that have converted universal health services into insurance-based health programs under structural reform strategies have struggled to supply the vulnerable with healthcare (Duggal, 2012).

In all stages, decision-makers need to measure the uncertainty in the success of the health system, recognize variables that impact it and articulate strategies that can produce improved outcomes in a range of environments. The scientific foundations of health policy at international and national levels can be improved by meaningful, comparative information on health system results and on key variables that clarify performance differences (Murray \& Frenk, 2000). A classic dilemma for health policymakers and analysts is how to build a healthcare system that can track or moderate the rapid increase in healthcare prices without unduly compromising the efficiency of and access to health facilities. While China and India's healthcare markets have grown rapidly, the regulatory response in both countries has lagged behind and has taken a different course, each leading to different ways of resolving the key regulatory issues related to quality of service, value for money, social consensus, and transparency. Presently, both China and India are working on establishing successful trust-based structures to support public policy agendas in their markets (Bloom et al., 2008).

Providing India's billion-plus persons with quality health care poses immense obstacles and prospects for the insurers, medical professionals and other service providers. The health care divide has started to be bridged by creative technology, systems and alliances formed by the Indian government and private corporations. There are developments on many fronts, from increasing health care services for the vulnerable to constructing clinics in smaller cities, to using clean drinking water technology and optimizing patient outcomes (Khan \& Banerji, 2014). The task is to find a way for Indian policymakers to change the current health sector situation and to make fair, accessible and reliable health care available to everyone, especially the poor and disadvantaged parts of society (S. S. Kumar \& Ramamoorthy, 2014). Through enacting regulations that lays down basic expectations of medical care, the secret to improving quality of the healthcare facilities in India and lowering costs at the same time can be found. Health care programs appear to be pricey and of poor consistency in the lack of those requirements and the inability of health insurance providers to standardize either price or quality (Rajivlochan, 2015).

Efficiency grows exponentially as health service providers and insurers combine together around health outcomes and value, and administration expenses decrease (Porter \& Teisberg, 2006). Developing nations that have turned universal health services into insurance-based health programs under structural reform strategies have struggled to supply the vulnerable with healthcare (Duggal, 2012). A TPA or an insurance agent will be able to have a comparative advantage over its competition only if the fees/packages could be frozen for a period of three or five years by way of a joint agreement. By performing spot checks, consultation at the time of cashless authorisation, agreement on the package cost, as well as some form of trend and data analysis, insurance companies and TPAs are trying to create barriers. Through enacting regulations that lays down basic expectations of medical care, the secret to refining the quality of healthcare facilities in India and lowering costs at the same time can be found. Healthcare programs appear to be pricey and of poor consistency in the lack of those requirements and the inability of health insurance providers to standardize either price or quality. Via regulatory mandate and a change in the mindset of health insurers, developing patient care expectations will change the balance in favour of the patient who 
is now at the hospital's mercy. To address this problem, the best solution is to provide consistent patient care requirements together with robust administrative frameworks to implement them (Rajivlochan, 2015).

Another exciting choice for improving results by collaboration with the private sector is performance reward contracts with health care services. It is essential for states, implementation authorities, and researchers working in India to collaborate on evidencebased approaches to improve the efficiency of health care and health outcomes. (M. McClellan, 2015; Mohanan, Hay, \& Mor, 2016). A rising focus has been placed on pursuing the promise of big data analytics to harness the potential of vast health data from private and government health care companies. While the domain ramifications of such cooperation are well known, in the data mining community, this form of data has been discussed to a limited degree. Experts believe that the main driver for the disparity in expenditure and returns in the healthcare sector is inefficiencies in the new healthcare structure, culminating in unparalleled levels of duplication. Increasing development of healthcare products, facilities, advancement in reasonably priced medical devices and a transition to universal health care needs to be accompanied by an evidence base that focuses on quality, protection, sustainability and acceptability in order to optimize the gains that can be achieved from a small budget for healthcare. In low- and middleincome countries (LMIC) such as India, an outcome based and sustainable healthcare prioritization system is critical to achieving the aspirational aim of universal healthcare. Their systematic examination is a pillar in educating current health policy in India, considering the growing prices of healthcare interventions, diagnostics and equipment. In an increasingly limited economic climate, goal setting is critical and while India has the potential to spend more in healthcare, the task is to set goals in a realistic manner such that any incremental expenditure produces improved health benefits (M. Kumar, Ebrahim, Taylor, Chokshi, \& Gabbay, 2014). S. S. Kumar and Ramamoorthy (2014) mention that the priority, for Indian policymakers is to identify ways to change the current health sector situation and make health care available to people, especially the poor and disadvantaged segments of society, in a fair, affordable and quality way. To address this problem, the best solution is to provide consistent patient care requirements together with robust administrative frameworks to implement them (Rajivlochan, 2015).

Government and private organizations will need to concentrate on aspects of cost, benefit design and knowledge disclosure in order to expand the reach and viability of private health insurance policies, and explain requirements on coverage and provider quality standards (Bhattacharjya \& Sapra, 2008). As far as health policy is concerned, experts have suggested that decision-makers need to measure the inconsistency in the efficiency of the health sector at all stages of the system, define variables that impact it and articulate strategies that can produce improved outcomes in a range of environments. Experts agree that for the states, development organizations and multilateral organisations, a compelling and operational structure for measuring the success of the health system is crucial (Murray \& Frenk, 2000). Companies must examine the emerging business strategies of managed care, centralized delivery and responsible care at a more strategic basis, which will force wholesale improvements in the health care sector and help create a more viable insurance model. Unfortunately, customers do not commit to private health insurance due to lack of government mandate (as is the case in auto insurance), unless they believe they bear a health threat.

Although policymakers in developed nations have been keen to experiment with healthcare delivery with result based contracts, most performance compensation schemes do not explicitly reward health changes (Mohanan et al., 2016). Insufficient 
research facilities and financing, changing policy priorities, weak intersectoral linkages and a lack of overall health research culture in India are the structural hurdles in the Indian research scenario that impair the efficient growth of health service research, with inadequate understanding of the value of such research by policymakers. State government health insurance plans have difficulties negotiating the services given, defined care plan rates and not clear pricing. Reflecting gaps in tertiary care coverage. Health insurance, as healthcare payers, has a role to play in promoting the growth of HTA as they can benefit from mechanisms that advise the distribution of evidence-based services and allow them to manage inflation in the premiums paid to individuals and government (M. Kumar et al., 2014).In their study, Manyika and Roxburgh (2011) list many fields in the healthcare sector that can benefit from the use of big data analytics, such as classification of patients on their health profiles to define focus audiences for preventive treatment or lifestyle improvements, implementation of payment structures that are immune to fraud, establishment of clarity of knowledge and usability of health data. There are limited attempts to analyze healthcare claims information and data to understand healthcare system shortfalls and inefficiencies, but they are limited to basic overview figures from the empirical viewpoint, such as population implies for different populations (Chandola, Sukumar, \& Schryver, 2013).

The key themes and areas that were identified as the focus areas in health insurance research in India are universal health coverage, escalating costs, lack of standardized guidelines for costs and services rendered by healthcare providers, the need for collaboration between the various players in the healthcare industry, need for performance based incentives for service providers, the need for standardized costs and procedures, the various healthcare models like managed care and ACOs, the recent trend of in-house TPAs, the lack of government mandate for health insurance purchase and the use of technology for managing claims and other services provided by the healthcare players. There are limitations to this study. The study has not included all the articles available on Indian health insurance and managed care models. Limited research in Indian context on health insurance is a concern and more researchers need to explore the current models of healthcare and make meaningful observations and contribution and pave the path for achievement of universal health coverage at reasonable costs.

\section{REFERENCES}

[1] Anchan, P. S., Jathanna, R., \& Marla, A. (2011). Evaluation of Health Insurance and Claim Process at Tertiary Care Hospital, Mangalore A Case Report. Journal of Health Management, 13(1), 97-112.

[2] Anita, J. (2010). Emerging Health Insurance in India-An overview. Paper presented at the 10th Global Conference of Actuaries Feb.

[3] Berman, P. A. (1998). Rethinking health care systems: Private health care provision in India. World Development, 26(8), 1463-1479.

[4] Bhat, R., \& Babu, S. K. (2004). Health insurance and third party administrators: Issues and challenges. Economic and Political weekly, 39 No. 28, 3149-3159.

[5] Bhat, R., \& Reuben, E. B. (2002). Management of claims and reimbursements: The case of mediclaim insurance policy. Vikalpa, 27(4), 15-28.

[6] Bhattacharjya, A. S., \& Sapra, P. K. (2008). Health insurance in China and India: segmented roles for public and private financing. Health Affairs, 27(4), 1005-1015.

[7] Bloom, G., Kanjilal, B., \& Peters, D. H. (2008). Regulating health care markets in China and India. Health Affairs, 27(4), 952-963.

[8] Boyer, K. K., \& Pronovost, P. (2010). What medicine can teach operations: What operations can teach medicine. Journal of Operations Management, 28(5), 367-371. 
[9] Chandola, V., Sukumar, S. R., \& Schryver, J. C. (2013). Knowledge discovery from massive healthcare claims data. Paper presented at the Proceedings of the 19th ACM SIGKDD international conference on Knowledge discovery and data mining.

[10] De Blok, C., Meijboom, B., Luijkx, K., \& Schols, J. (2013). The human dimension of modular care provision: opportunities for personalization and customization. International Journal of Production Economics, 142(1), 16-26.

[11] Dev, S. M., \& Mooij, J. (2002). Social sector expenditures in the 1990s: Analysis of central and state budgets. Economic and Political weekly, 853-866.

[12] DeVore, S., \& Champion, R. W. (2011). Driving population health through accountable care organizations. Health Affairs, 30(1), 41-50.

[13] Dixon, A., Greene, J., \& Hibbard, J. (2008). Do Consumer-Directed Health Plans Drive Change in Enrollees' Health Care Behavior? Health Affairs, 27(4), 1120-1131.

[14] Dobrzykowski, D., Saboori Deilami, V., Hong, P., \& Kim, S.-C. (2014). A structured analysis of operations and supply chain management research in healthcare (19822011). International Journal of Production Economics, 147, Part B(0), 514-530. doi:

[15] Doran, T., Fullwood, C., Gravelle, H., Reeves, D., Kontopantelis, E., Hiroeh, U., \& Roland, M. (2006). Pay-for-performance programs in family practices in the United Kingdom. New England Journal of Medicine, 355(4), 375-384.

[16] Duggal, R. (2012). Challenges in Financing Healthcare. Economic \& Political Weekly, 47(35), 23.

[17] Fisher, E. S., Shortell, S. M., Kreindler, S. A., Van Citters, A. D., \& Larson, B. K. (2012). A framework for evaluating the formation, implementation, and performance of accountable care organizations. Health Affairs, 31(11), 2368-2378.

[18] Ghosh, S. (2010). Catastrophic payments and impoverishment due to out-of-pocket health spending: the effects of recent health sector reforms in India.

[19] IBEF. (2020). Indian Healthcare Industry Analysis. Retrieved from

[20] Khan, M. I., \& Banerji, A. (2014). Health Care Management in India: some issues and challenges. Journal of Health Management, 16(1), 133-147.

[21] Kumar, A. S., Chen, L. C., Choudhury, M., Ganju, S., Mahajan, V., Sinha, A., \& Sen, A. (2011). Financing health care for all: challenges and opportunities. The Lancet, 377(9766), 668-679.

[22] Kumar, M., Ebrahim, S., Taylor, F., Chokshi, M., \& Gabbay, J. (2014). Health technology assessment in India: The potential for improved healthcare decision-making. NATIONAL MEDICAL JOURNAL OF INDIA, 27(3), 159-163.

[23] Kumar, R., Rangarajan, K., \& Ranganathan, N. (2011). Health Insurance in India-A Study of Provider's Perceptions in Delhi \& the NCR. Journal of Health Management, 13(3), 259-277.

[24] Kumar, S. S., \& Ramamoorthy, R. (2014). Health Insurance Market in India-The Way Forward. Health and Medical Care Services: Claims on National Resources, 178.

[25] Lawn, S. D., Harries, A. D., Anglaret, X., Myer, L., \& Wood, R. (2008). Early mortality among adults accessing antiretroviral treatment programmes in sub-Saharan Africa. AIDS (London, England), 22(15).

[26] Li, C., Yu, X., Butler, J. R., Yiengprugsawan, V., \& Yu, M. (2011). Moving towards universal health insurance in China: performance, issues and lessons from Thailand. Social Science \& Medicine, 73(3), 359-366.

[27] Li, L., \& Benton, W. (1996). Performance measurement criteria in health care organizations: review and future research directions. European Journal of Operational Research, 93(3), 449-468.

[28] Liu, Y., Hsiao, W. C., Li, Q., Liu, X., \& Ren, M. (1995). Transformation of China's rural health care financing. Social Science \& Medicine, 41(8), 1085-1093. 
[29] Mahal, A. (2002). Assessing private health insurance in India: potential impacts and regulatory issues. Economic and Political weekly, 37(6), 559-571.

[30] Manyika, J., \& Roxburgh, C. (2011). The great transformer: The impact of the Internet on economic growth and prosperity. McKinsey Global Institute, 1, 0360-8581.

[31] Mavalankar, D., \& Bhat, R. (2000). Health insurance in India: opportunities, challenges and concerns. Ahmedabad: Indian Institute of Management, 1-16.

[32] McClellan, M. (2015). ACcountable care organizations and evidence-based payment reform. Jama, 313(21), 2128-2130. doi:10.1001/jama.2015.5087

[33] McClellan, M., McKethan, A. N., Lewis, J. L., Roski, J., \& Fisher, E. S. (2010). A national strategy to put accountable care into practice. Health Affairs, 29(5), 982-990.

[34] McCorry, D. (2014). Direct primary care: an innovative alternative to conventional health insurance. Backgrounder, 2939, 1-13.

[35] McFadden, K. L., Stock, G. N., Gowen III, C. R., \& Cook, P. (2006). Exploring strategies for reducing hospital errors. Journal of Healthcare Management, 51(2), 123.

[36] Mehta, M. K. (2010, August 15, 2010). PSU insurance companies to float own TPA, Newspaper The Economic Times.

[37] Mohanan, M., Hay, K., \& Mor, N. (2016). Quality Of health care in India: challenges, priorities, and the road ahead. Health Affairs, 35(10), 1753-1758.

[38] Murray, C. J., \& Frenk, J. (2000). A framework for assessing the performance of health systems. Bulletin of the World Health Organization, 78, 717-731.

[39] Peters, D. H. (2002). The role of oversight in the health sector: the example of sexual and reproductive health services in India. Reproductive Health Matters, 10(20), 82-94.

[40] Porter, M. E., \& Teisberg, E. O. (2006). Redefining health care: creating value-based competition on results: Harvard business press.

[41] Rajivlochan, M. (2015). Improving Healthcare Services at Reduced Prices. Economic \& Political Weekly, 50(1), 33.

[42] Reddy, S., Selvaraj, S., Rao, K. D., Chokshi, M., Kumar, P., Arora, V., . . . Ganguly, I. (2011). A critical assessment of the existing health insurance models in India. a report submitted to the Planning Commission of India, January, New Delhi.

[43] Robinson, J. C., Williams, T., \& Yanagihara, D. (2009). Measurement of and reward for efficiency in California's pay-for-performance program. Health Affairs, 28(5), 14381447.

[44] Ros, C. C., Groenewegen, P. P., \& Delnoij, D. M. (2000). All rights reserved, or can we just copy? Cost sharing arrangements and characteristics of health care systems. Health Policy, 52(1), 1-13.

[45] Rosenthal, M. B., \& Dudley, R. A. (2007). Pay-for-performance: will the latest payment trend improve care? Jama, 297(7), 740-744.

[46] Sen, G., Iyer, A., \& George, A. (2002). Structural reforms and health equity: a comparison of NSS surveys, 1986-87 and 1995-96. Economic and Political weekly, $1342-1352$.

[47] Smith, B. K., Nachtmann, H., \& Pohl, E. A. (2011). Quality measurement in the healthcare supply chain. Quality Management Journal, 18(4), 50-60.

[48] Spaan, E., Mathijssen, J., Tromp, N., McBain, F., Have, A. t., \& Baltussen, R. (2012). The impact of health insurance in Africa and Asia: a systematic review. Bulletin of the World Health Organization, 90, 685-692.

[49] Sulger, J. F. (1996). A closer look at capitation. Am J Manag Care, 2, 1091-1096.

[50] Thomas, K., \& Vel, R. S. (2011). Private health insurance in India evaluating emerging business models. Journal of Health Management, 13(4), 401-417. 
The Role of Health Insurance and Managed Care in India

[51] Thomas, T. K. (2011). Health insurance in India: need for managed care expertise. The American journal of managed care, 17(2), e26-33.

[52] Trude, S., Au, M., \& Christianson, J. B. (2006). Health plan pay-for-performance strategies. American Journal of Managed Care, 12(9), 537. 